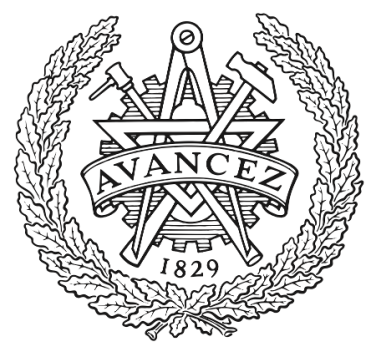

CHALMERS

UNIVERSITY OF TECHNOLOGY

\title{
DICE and the Carbon Budget for Ambitious Climate Targets
}

Downloaded from: https://research.chalmers.se, 2023-04-26 11:50 UTC

Citation for the original published paper (version of record):

Azar, C., Johansson, D. (2021). DICE and the Carbon Budget for Ambitious Climate Targets. Earth's Future, 9(7). http://dx.doi.org/10.1029/2021EF002041

N.B. When citing this work, cite the original published paper. 


\section{Earth's Future}

\section{COMMENTARY}

10.1029/2021EF002041

Key Points:

- We use the DICE model to estimate the available carbon budget for meeting Paris-styled temperature targets

- We find that the available carbon budget is a factor of five lower than estimates by more advanced climate models

- We then update DICE using state-ofthe-art models of earth system and explain why DICE estimates find a too low carbon budget

Supporting Information: Supporting Information may be found in the online version of this article.

Correspondence to:

C. Azar,

christian.azar@chalmers.se

\section{Citation:}

Azar, C., \& Johansson, D. J. A. (2021). DICE and the carbon budget for ambitious climate targets. Earth's Future, 9, e2021EF002041. https://doi. org/10.1029/2021EF002041

Received 16 FEB 2021

Accepted 21 JUN 2021

Author Contributions:

Conceptualization: Christian Azar,

Daniel J. A. Johansson

Formal analysis: Christian Azar,

Daniel J. A. Johansson

Funding acquisition: Daniel J. A. Johansson

Investigation: Christian Azar, Daniel J. A. Johansson

Methodology: Christian Azar, Daniel J. A. Johansson

Software: Daniel J. A. Johansson Writing - original draft: Christian Azar, Daniel J. A. Johansson

(c) 2021. The Authors. Earth's Future published by Wiley Periodicals LLC on behalf of American Geophysical Union. This is an open access article under the terms of the Creative Commons Attribution-NonCommercial-NoDerivs License, which permits use and distribution in any medium, provided the original work is properly cited, the use is non-commercial and no modifications or adaptations are made.

\section{DICE and the Carbon Budget for Ambitious Climate Targets}

\author{
Christian Azar $^{1}$ (D) and Daniel J. A. Johansson ${ }^{1}$ \\ ${ }^{1}$ Department of Space, Earth \& Environment, Division of Physical Resource Theory, Chalmers University of \\ Technology, Göteborg, Sweden
}

Abstract The Dynamic Integrated Climate-Economy (DICE) model is one of the most influential Integrated Assessment Models available. Its founder Professor William Nordhaus was recently awarded Sveriges Riksbank Prize in Economic Sciences in Memory of Alfred Nobel due to his pioneering work on the economics of climate change. In a recent paper in American Economic Journal: Economic Policy, Nordhaus uses the model to conclude that a $2.5^{\circ} \mathrm{C}$ target is almost out of reach. In this paper, we update DICE 2016 R2 with state-of-the-art models of the carbon cycle, heat uptake into the oceans, and the role of non- $\mathrm{CO}_{2}$ forcers. We find that the allowable remaining carbon budget (over the period 2015-2100) to meet a $2.5^{\circ} \mathrm{C}$ target to be $2,360 \mathrm{GtCO}_{2}$ whereas the estimate obtained using DICE $2016 \mathrm{R} 2$ is about $460 \mathrm{GtCO}_{2}$. Nordhaus's estimate of the remaining carbon budget for this target is hence five times lower than estimates made by our updated DICE. We also compare our results with estimates by the Intergovernmental Panel on Climate Change (IPCC), and find our results to be in line with the carbon budgets presented in IPCC SR 1.5. We explain the reasons behind the difference between our result and that of Nordhaus and propose that an updated climate module in DICE is warranted.

Plain Language Summary The Dynamic Integrated Climate-Economy (DICE) model is one of the most commonly used Integrated Assessment Models to analyse climate policy. It was developed by William Nordhaus who subsequently received the Nobel Prize in economics largely as a result of his work with DICE. Nordhaus has used the DICE model to conclude that ambitious climate target appears infeasible as a consequence of inertia in the climate system. In this paper, we show that there are significant problems with the geophysical modules in DICE. This implies that DICE estimates the carbon budget for ambitious climate targets to be many times smaller than the carbon budget estimated by the IPCC. We update DICE with state of the art climate modules and find results in line with IPCC. Through this procedure we can explain why DICE significanty underestimates the carbon budgets. Since DICE has such a strong standing among modellers, economists, and policy makers, understanding that DICE yields a too low carbon budget for ambitious climate targets and why that is the case is important. We also believe that updating the climate science modules of DICE is warranted if it is to be able to capture climate policy aspects relevant for the two degree target.

\section{Introduction}

Professor William Nordhaus was awarded the Sveriges Riksbank Prize in Economic Sciences in Memory of Alfred Nobel in December 2018 due to his pioneering work on the economics of climate change. A substantial part of Professor Nordhaus's research in this field has been to develop and continuously improve the Dynamic Integrated Climate-Economy (DICE) model. The DICE model pioneered the field when it was first presented in the early 1990s (Nordhaus, 1992, 1994), and it is still highly influential within the field of the economics of climate change.

In a recent paper in the American Economic Journal: Economic Policy, Nordhaus presents results from the most recent update of DICE, version 2016R2 (Nordhaus, 2018b). Among a range of results presented in the paper, he finds (see p. 334) that "the international target for climate change with a limit of $2^{\circ} \mathrm{C}$ appears to be infeasible with reasonably accessible technologies even with very ambitious abatement strategies. This is so because of the inertia of the climate system, rapid projected economic growth in the near term, and revisions in several elements of the model. A target of $2.5^{\circ} \mathrm{C}$ is technically feasible but would require extreme and virtually universal global policy measures in the near future. 
Writing - review \& editing: Christian Azar, Daniel J. A. Johansson
Reaching ambitious temperature requires strong and internationally coordinated climate policies. However, in this paper, we find that reaching such climate targets is likely much easier than what Nordhaus concludes from running DICE. The reason for this is that DICE 2016R2 significantly underestimates the allowable emission space for carbon dioxide emissions when it comes to reaching temperature targets in the range of $1.5-2.5^{\circ} \mathrm{C}$.

The recent special report "Global Warming of $1.5^{\circ} \mathrm{C}$ " by the Intergovernmental Panel on Climate Change (Rogelj et al., 2018), hereafter referred to as IPCC SR1.5, finds significantly higher carbon emission trajectories toward these low-temperature targets, and even concludes that "limit global warming to $1.5^{\circ} \mathrm{C}$ with no or limited overshoot” is not necessarily out of reach. They also provide emissions, energy, and land use scenarios generated by Integrated Assessment Models that reach stabilization at around $1.5^{\circ} \mathrm{C}$ above the pre-industrial level.

The aim of this note is to (a) to recalibrate and update some key features of the physical aspects of DICE, (b) use this updated version of DICE to generate estimates of the allowable carbon budget to meet Paris-styled temperature targets, and (c) explain why the most recent version of the DICE model (version 2016R2) generates such low estimates of the allowable carbon budgets for ambitious climate targets compared to the IPCC SR1.5 report.

In short, we have identified three reasons explaining why DICE generates this low-carbon budget for stringent climate targets. The first is related to the carbon cycle, the second to the inertia of the climate system (basically the heat uptake by the oceans) and, the third to the assumed exogenous trajectory for the radiating forcing from non- $\mathrm{CO}_{2}$ climate forcers.

In several earlier studies, the geophysical module in DICE (various versions of it) has been analyzed or modified (Azar \& Sterner, 1996; Dietz et al., 2020; Faulwasser et al., 2018; Glotter et al., 2014; Hänsel et al., 2020; Johansson et al., 2020; Joos et al., 1999; Rickels et al., 2018; Su et al., 2017; van Vuuren et al., 2011), but none has explicitly analyzed what it means for the remaining cumulative carbon emission budget for a given stabilization target, and none has compared the implications for the most recent version of DICE (2016R2).

Furthermore, when analyzing which changes in DICE from its 1992 version to its most recent version had the largest impact on the social cost of carbon and the temperature in the year 2100 in the business as usual scenario, Nordhaus identified changes in the way he represents the carbon cycle as the most important modification (Nordhaus, 2018a). This suggests that further analysis of the way the carbon cycle is modeled is of interest.

\section{Methodology}

In this note, we solely focus on how the geophysical module of DICE matters for emission pathways and cumulative emissions budgets compatible with ambitious-temperature targets and leave economic issues, such as finding the optimal climate target, the cost of stabilization, and social cost of carbon aside (for this reason, the climate damage function is set to zero in our runs).

The following changes to DICE 2016R2 model were introduced (see Supporting Information for more details):

1. The linearized carbon cycle representation in DICE was changed to the carbon cycle representation in the simple climate model FAIR (Millar et al., 2017; Smith et al., 2018). The FAIR model was used to assess the climate impact of various emissions pathways in IPCC SPR 1.5 (Rogelj et al., 2018), and it takes into account non-linearities in the carbon cycle and climate-carbon cycle feedbacks. We chose to use FAIR since it reproduces more complex climate models well and since it is widely used by the IPCC, but of course, other approaches could have been used, for example (Meinshausen, Sith et al., 2011; Sterner \& Johansson, 2017; Strassmann \& Joos, 2018).

In his American Economic Journal article, Nordhaus (2018b) writes that the 2016 version of DICE incorporates new research on the carbon cycle. Earlier versions of the DICE model were calibrated to fit the short-run carbon cycle (primarily the first 100 years). Because the new model is in part designed to calculate long-run trends, such as the impacts on the melting of large ice sheets, it was decided to change the calibration to fit the atmospheric retention of $\mathrm{CO}_{2}$ for periods up to 4,000 years. Based on studies of 


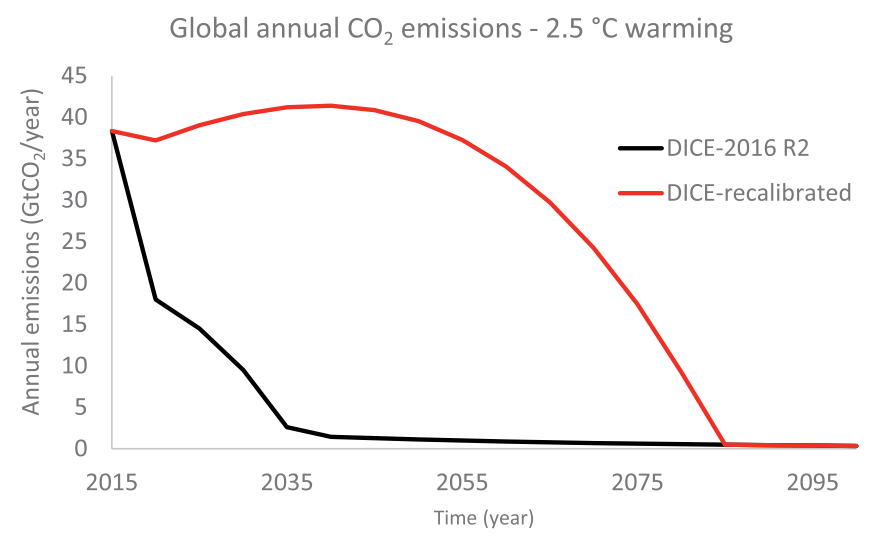

Figure 1. $\mathrm{CO}_{2}$ emission pathways in Dynamic Integrated ClimateEconomy (DICE) for 2016 R2 version and the recalibrated version presented in this paper.
Archer et al. (2009), the 2016 version of the three-box model does a much better job of simulating the long-run behavior of larger models with full ocean chemistry. This change has a major impact on the long-run carbon concentrations."

This improvement over previous versions is worth acknowledging. However, his approach still does not take into account non-linearities in the carbon cycle. This is important since larger fractions of $\mathrm{CO}_{2}$ emissions pulse stays in the atmosphere, the higher the $\mathrm{CO}_{2}$ concentration is (Archer et al., 2009; Caldeira \& Kasting, 1993; Maier-Reimer \& Hasselmann, 1987). In DICE 2016R2, the carbon cycle appears to have been linearized around a relatively high concentration of $\mathrm{CO}_{2}$. This implies that more carbon stays in the atmosphere in DICE 2016R2 for each pulse emission of $\mathrm{CO}_{2}$ than in more advanced representations that take this non-linearity into account for atmospheric $\mathrm{CO}_{2}$ concentrations compatible with Paris-styled temperature targets. As a consequence, the temperature effect of each ton of $\mathrm{CO}_{2}$ emitted is likely to be too high in DICE 2016R2 for concentration levels compatible with stabilization of global mean surface temperature around $2^{\circ} \mathrm{C}$ (see Supporting Information for more information).

2. The temperature response to changes in radiative forcing in DICE 2016R2 is somewhat at odds with the response in state-of-the-art climate system models (see Supporting Information for more information). We have thus recalibrated the Energy Balance Model (EBM), so that its parameterization represents the average characteristics of climate models used in the Coupled Model Intercomparison Project Phase 5 (CMIP5) (Geoffroy et al., 2013). The equilibrium response, that is, the climate sensitivity, is fine in DICE (being $3.1^{\circ} \mathrm{C}$ for a doubling of the $\mathrm{CO}_{2}$ concentration), and it is hence left unchanged.

3. The scenario assumption for the radiative forcing from non- $\mathrm{CO}_{2}$ climate forcers in DICE 2016R2 is substantially higher than what is estimated in other climate scenario work, for example, Representative Concentration Pathways (RCP) 2.6 and $4.5\left(\mathrm{~W} / \mathrm{m}^{2}\right)$, when analyzing pathways compatible with stabilization of global mean surface temperature around $2-3^{\circ} \mathrm{C}$ above the pre-industrial level (see Supporting Information for more information). The IPCC SR 1.5 states that "non- $\mathrm{CO}_{2}$ emissions in pathways that limit global warming to $1.5^{\circ} \mathrm{C}$ show deep reductions." Hence, abatement of non- $\mathrm{CO}_{2}$ emissions is critical and economically justified when aiming for stringent climate stabilization levels, but in DICE 2016 R2, they are exogenously given at a somewhat high level. In our modification of the model, we have changed the radiative forcing scenario for non- $\mathrm{CO}_{2}$ forcers so that it matches an intermediate value of the forcing in the RCPs 2.6 and 4.5 (Meinshausen, Raper et al., 2011).

\section{Results}

In Figure 1, we report our results. We find that the changes described above lead to a substantial increase of the $\mathrm{CO}_{2}$ emissions space for a stabilization of the global mean surface temperature at $2.5^{\circ} \mathrm{C}$ above the pre-industrial level compared to Nordhaus's finding $\left(2.5^{\circ} \mathrm{C}\right.$ is basically the lowest stabilization target that can be met in DICE $2016 \mathrm{R} 2$ ). The cumulative carbon budget between 2015 and 2100 for a $2.5^{\circ} \mathrm{C}$ stabilization target in DICE $2016 \mathrm{R} 2$ is about $460 \mathrm{GtCO}_{2}$, while in the recalibrated version, it is $2,360 \mathrm{GtCO}_{2}$, that is, an increase by roughly a factor of five.

All three changes described above contribute to increase the $\mathrm{CO}_{2}$ budget for a $2.5^{\circ} \mathrm{C}$ target. The impact of each change on the emission budget depends on the order with which the changes are implemented in the model due interdependencies between the changes. Changing the carbon cycle increases the $\mathrm{CO}_{2}$ budget with about $400-800 \mathrm{GtCO}_{2}$, and the budget impact of changing the EBM is largely similar to that of the carbon cycle, while changing the non- $\mathrm{CO}_{2}$ pathway has a slightly larger impact on the cumulative budget.

Furthermore, we estimate the carbon budget for the $2^{\circ} \mathrm{C}$ target (see Figure S4). In DICE 2016 R2, this target cannot be met, so no budget is available. In the recalibrated version the cumulative emissions are about 1,400 $\mathrm{GtCO}_{2}$ for the period 2015-2100. This is in line with the remaining estimated cumulative $\mathrm{CO}_{2}$ emissions budget for the $2^{\circ} \mathrm{C}$ target taken from IPCC SR1.5 where it is $1620 \mathrm{GtCO}_{2}$ if the target should be met with a 
$50 \%$ chance and $1,290 \mathrm{GtCO}_{2}$ if the target should be met with a $67 \%$ chance (Rogelj et al., 2018). Hence, our updated DICE gives results in line with IPCC SR1.5 (see Supporting Information for further details).

For the $2^{\circ} \mathrm{C}$ target the estimated budget after 2015 in our updated DICE is about 3 times as large as the budget for a $2.5^{\circ} \mathrm{C}$ target estimated using DICE $2016 \mathrm{R} 2$.

Finally, we also want to point out that for large cumulative $\mathrm{CO}_{2}$ emissions, in the order of $10,000 \mathrm{GtCO}_{2}$, DICE 2016R2 model gives roughly correct results for the relationship between cumulative emissions and long-run $\mathrm{CO}_{2}$ concentration. Hence, in a scenario with large cumulative $\mathrm{CO}_{2}$ emissions the carbon cycle in DICE 2016R2 works better to estimate long-run concentration levels.

\section{Conclusion}

The DICE model is one of the most influential IAMs. In this paper, we have analyzed the geophysical module of the DICE 2016R2 model (Nordhaus, 2018a). We did that by modifying the carbon cycle, the energy balance model, and the assumed radiative forcing from non- $\mathrm{CO}_{2}$ greenhouse gases and aerosols. We then used this updated DICE model to estimate the carbon budget available to meet the $1.5,2$, and $2.5^{\circ} \mathrm{C}$ targets (see Figure S4). Our estimates are compatible with the estimates made by state-of-the-art integrated assessment models as reported by the IPCC (Rogelj et al., 2018).

We then compared Nordhaus version (DICE 2016 R2) with our results and found that the estimated carbon budget for a $2.5^{\circ} \mathrm{C}$ target is found to be five times higher in our updated DICE than in DICE 2016R2. More specifically, in DICE 2016R2, the carbon emissions associated with the $2.5^{\circ} \mathrm{C}$ target drop to roughly zero by the year 2040. However, with our modifications to DICE 2016R2, emissions can remain roughly constant to the year 2050 and then fall to around zero by 2085 (see Figure 1).

Clearly, this conspicuous difference in carbon emission trajectories has a major impact on the political, economic, and technical effort required to meet ambitious temperature targets. For that reason, we believe that caution is required when using DICE 2016 R2 to draw firm conclusions about the feasibility to meet stringent-temperature targets. Although meeting the 2 or $2.5^{\circ} \mathrm{C}$ targets still requires a huge political and technological effort, it is significantly less than what is suggested by the DICE 2016 R2 model.

It can also be noted that the estimated carbon budget for the $1.5^{\circ} \mathrm{C}$ target as given in IPCC SR1.5 is higher than the emission budget for the $2.5^{\circ} \mathrm{C}$ target in DICE $2016 \mathrm{R} 2$. This means that Nordhaus's policy conclusion that pertains to the $2.5^{\circ} \mathrm{C}$ target is more relevant for the $1.5^{\circ} \mathrm{C}$ target.

One reason for the difference in results has to do with how Nordhaus has implemented the carbon cycle in his model. His approach gives too large an atmospheric concentration response for each pulse emission (given background $\mathrm{CO}_{2}$ concentrations compatible with the Paris-agreement targets). However, his approach works fine for much higher atmospheric concentrations. For cumulative carbon budgets reaching approximately $10,000 \mathrm{GtCO}_{2}$, his carbon cycle model becomes a better approximation of state-of-the-art assessments.

Our results suggest that the Earth system component of DICE 2016R2 needs updating to bring it in line with state-of-the-art Earth system model results. We recommend that DICE be so updated before it is used to assess costs and greenhouse gas emissions trajectories, especially for meeting ambitious climate targets and determining the social cost of carbon.

\section{Data Availability Statement}

The GAMS code for the revised version of DICE is available at https://github.com/DanielJohansson Chalmers/DICE-Revised.

The authors acknowledge the financial support from Carl Bennet Foundation $\mathrm{AB}$, Adlerbertska forskningsstiftelsen and from MISTRA through the projects Mistra Carbon Exit and Mistra Electric Transition. The authors also thank Brian O'Neill, Martin Persson, Sonia Yeh, and two anonymous reviewers for valuable comments.

\section{References}

Archer, D., Eby, M., Brovkin, V., Ridgwell, A., Cao, L., Mikolajewicz, U., et al. (2009). Atmospheric lifetime of fossil fuel carbon dioxide. Annual Review of Earth and Planetary Science, 37, 117-134. https://doi.org/10.1146/annurev.earth.031208.100206

Azar, C., \& Sterner, T. (1996). Discounting and distributional considerations in the context of global warming. Ecological Economics, 19(2), 169-184. https://doi.org/10.1016/0921-8009(96)00065-1 
Caldeira, K., \& Kasting, J. F. (1993). Insensitivity of global warming potentials to carbon dioxide emission scenarios. Nature, 366, $251-253$. https://doi.org/10.1038/366251a0

Dietz, S., Ploeg, van der, F., Rezai, A., \& Venmans, F. (2020). Are economists getting climate dynamics right and does it matter? CESifo Working Paper No. 8122. Retrieved from https://papers.ssrn.com/sol3/papers.cfm?abstract_id=3545718

Faulwasser, T., Nydestedt, R., Kellett, C. M., \& Weller, S. R. (2018). Towards a FAIR-DICE IAM: Combining DICE and FAIR models. IFAC-PapersOnLine, 51(5), 126-131. https://doi.org/10.1016/j.ifacol.2018.06.222

Geoffroy, O., Saint-Martin, D., Olivié, D. J. L., Voldoire, A., Bellon, G., \& Tytéca, S. (2013). Transient climate response in a two-layer energy-balance model. Part I: Analytical solution and parameter calibration using CMIP5 AOGCM experiments. Journal of Climate, 26(6), 1841-1857. https://doi.org/10.1175/JCLI-D-12-00195.1

Glotter, M. J., Pierrehumbert, R. T., Elliott, J. W., Matteson, N. J., \& Moyer, E. J. (2014). A simple carbon cycle representation for economic and policy analyses. Climatic Change, 126(3-4), 319-335. https://doi.org/10.1007/s10584-014-1224-y

Hänsel, M., Drupp, M. A., Johansson, D. J. A., Nessje, F., Azar, C., Freeman, M. C., et al. (2020). Climate economics support for the UN targets. Nature Climate Change, 10, 781-789. https://doi.org/10.1038/s41558-020-0833-x

Johansson, D. J. A., Azar, C., Lehtveer, M., \& Peters, G. (2020). The role of negative carbon emissions in reaching the Paris climate targets: The impact of target formulation in integrated assessment models. Environmental Research Letters, 15, 124024. https://doi. org/10.1088/1748-9326/abc3fo

Joos, F., Muller-Furstenberger, G., \& Stephan, G. (1999). Correcting the carbon cycle representation: How important is it for the economics of climate change? Environmental Modeling \& Assessment, 4, 133-140. https://doi.org/10.1023/a:1019004015342

Maier-Reimer, E., \& Hasselmann, K. (1987). Transport and storage of $\mathrm{CO}_{2}$ in the ocean-An inorganic ocean-circulation carbon cycle model. Climate Dynamics, 2(2), 63-90. https://doi.org/10.1007/bf01054491

Meinshausen, M., Raper, S. C. B., \& Wigley, T. M. L. (2011). Emulating coupled atmosphere-ocean and carbon cycle models with a simpler model, MAGICC6 - Part 1: Model description and calibration. Atmospheric Chemistry and Physics, 11, 1417-1456. https://doi. org/10.5194/acp-11-1417-2011

Meinshausen, M., Smith, S. J., Calvin, K. V., Daniel, J. S., Kainuma, M. L. T., Lamarque, J.-F., et al. (2011). The RCP greenhouse gas concentrations and their extension from 1765 to 2300. Climatic Change, 109, 213-241. https://doi.org/10.1007/s10584-011-0156-Z

Millar, R. J., Nicholls, Z. R., Friedlingstein, P., \& Allen, M. R. (2017). A modified impulse-response representation of the global near-surface air temperature and atmospheric concentration response to carbon dioxide emissions. Atmospheric Chemistry and Physics, 17, 7213-7228. https://doi.org/10.5194/acp-17-7213-2017

Nordhaus, W. D. (1992). An optimal transition path for controlling greenhouse gases. Science, 258(5086), 1315-1319. https://doi. org/10.1126/science.258.5086.1315

Nordhaus, W. D. (1994). Managing the global commons: The economics of climate change. MIT Press.

Nordhaus, W. D. (2018a). Evolution of modeling of the economics of global warming: Changes in the DICE model. Climatic Change, 148(4), 623-640. https://doi.org/10.1007/s10584-018-2218-y

Nordhaus, W. D. (2018b). Projections and uncertainties about climate change in an era of minimal climate policies. American Economic Journal: Economic Policy, 10(3), 333-360. https://doi.org/10.1257/pol.20170046

Rickels, W., Reith, F., Keller, D., Oschlies, A., \& Quaas, M. F. (2018). Integrated assessment of carbon dioxide removal. Earth's Future, 6(3), 565-582. https://doi.org/10.1002/2017ef000724

Rogelj, J., Shindell, D., Jiang, K., Fifita, S., Forster, P., Ginzburg, V., et al. (2018). Mitigation pathways compatible with $1.5^{\circ} \mathrm{C}$ in the context of sustainable development. In V. Masson-Delmotte, P. Zhai, H. O. Pörtner, D. Roberts, J. Skea, P. R. Shukla, et al. (Eds.), Global warming of $1.5^{\circ} \mathrm{C}$. An IPCC Special Report on the impacts of global warming of $1.5^{\circ} \mathrm{C}$ above pre-industrial levels and related global greenhouse gas emission pathways in the context of strengthening the global response to the threat of climate change, sustainable development, and efforts to eradicate poverty.

Smith, C. J., Forster, P. M., Allen, M., Leach, N., Millar, R. J., Passerello, G. A., \& Regayre, L. A. (2018). FAIR v1.3: A simple emissions-based impulse response and carbon cycle model. Geoscientific Model Development, 11, 2273-2297. https://doi.org/10.5194/gmd-11-2273-2018

Sterner, E. O., \& Johansson, D. J. A. (2017). The effect of climate-carbon cycle feedbacks on emission metrics, Environmental Research Letters 12, 034019. https://doi.org/10.1088/1748-9326/aa61dc

Strassmann, K. M., \& Joos, F. (2018). The Bern Simple Climate Model (BernSCM) v1.0: An extensible and fully documented open-source re-implementation of the Bern reduced-form model for global carbon cycle-climate simulations. Geoscientific Model Development, 11, 1887-1908. https://doi.org/10.5194/gmd-11-1887-2018

$\mathrm{Su}$, X., Takahashi, K., Fujimori, S., Hasegawa, T., Tanaka, K., Kato, E., et al. (2017). Emission pathways to achieve $2.0^{\circ} \mathrm{C}$ and $1.5^{\circ} \mathrm{C}$ climate targets. Earth's Future, 5(6), 592-604. https://doi.org/10.1002/2016ef000492

van Vuuren, D. P., Lowe, J., Stehfest, E., Gohar, L., Hof, A. F., Hope, C., et al. (2011). How well do integrated assessment models simulate climate change? Climatic Change, 104, 255-285. https://doi.org/10.1007/s10584-009-9764-2 